\title{
The Role of Preemptive Infiltration Anesthesia in the Management of Postoperative Pain Following Septoplasty
}

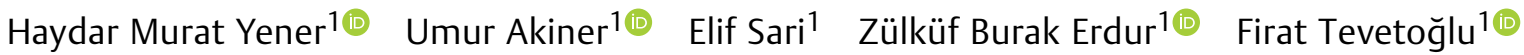 \\ Emine Deniz Gözen ${ }^{1}{ }^{10}$ \\ ${ }^{1}$ Department of Otorhinolaryngology, Istanbul University Cerrahpasa \\ Medical Faculty, Istanbul, Turkey \\ Int Arch Otorhinolaryngol 2022;26(4):e725-e729.

\begin{abstract}
Address for correspondence Dr. Fırat Tevetoğlu, MD, Department of Otorhinolaryngology, İstanbul Üniversitesi - Cerrahpaşa Tıp Fakültesi, KBB ABD, Kocamustafapaşa Cd. No:53, 34098, Fatih, İstanbul, Turkey (e-mail: firattevetoglu@gmail.com).
\end{abstract}

\begin{abstract}
Introduction Septoplasty is one of the most common surgical procedures in rhinology practice. Two major problems encountered after septoplasty are pain and bleeding. Preoperative administration of analgesics before the surgical stimulus, which is the main concept of preemptive analgesia, decreases postoperative pain.

Objective The present study was designed to investigate whether preincisional lidocaine infiltration to the subperichondrial area during septoplasty surgery reduced or not postoperative pain and analgesic use.

Methods The present prospective, randomized, placebo controlled, double-blind trial was conducted on 64 consecutive patients with nasal septum deviation. Patients were randomly divided into 2 groups; the study group received $2 \% 20 \mathrm{mg}$ lidocaine/cc $(n=31)$, and the control group received $6 \mathrm{cc} 0.9 \% \mathrm{NaCl}(n=33)$. A standard questionnaire was given to each patient to mark his or her pain score between 0 and 10 at the $1^{\text {st }}, 3^{\text {rd }}, 6^{\text {th }}, 12^{\text {th }}$, and $24^{\text {th }}$ hours.

Results The mean and the range of visual analogue scale (VAS) scores of the patients in the study group at the $1^{\text {st }}, 3^{\text {rd }}, 12^{\text {th }}$, and $24^{\text {th }}$ hours were $4.03 \pm 3.08(0-10)$; $3.42 \pm 2.39(0-8) ; 2.97 \pm 2.22(0-8) ; 2.87 \pm 2.61(0-9)$; and $1.94 \pm 2.06(0-9)$ respectively. The mean and the range of VAS scores of the patients in the control group at the

Keywords

- preemptive anesthesia

- septoplasty

- pain score

- VAS $1^{\text {st }}, 3^{\text {rd }}, 12^{\text {th }}$, and $24^{\text {th }}$ hours were $4.12 \pm 2.7(0-10) ; 3.45 \pm 2.4(0-10) ; 2.94 \pm 2.7(0-$ $10) ; 2.79 \pm 2.34(0-10)$; and $1.5 \pm 1.8(0-6)$, respectively. The statistical analysis revealed no significant difference among the groups.

Conclusion The preemptive local anesthetic administration to the incision area and under the mucoperichondrial flap before septoplasty does not decrease the level of postoperative pain.
\end{abstract}

received

December 18, 2020

accepted

April 17, 2021
DOI https://doi.org/ $10.1055 / \mathrm{s}-0042-1743203$. ISSN 1809-9777. (c) 2022. Fundação Otorrinolaringologia. All rights reserved.

This is an open access article published by Thieme under the terms of the Creative Commons Attribution-NonDerivative-NonCommercial-License, permitting copying and reproduction so long as the original work is given appropriate credit. Contents may not be used for commercial purposes, or adapted, remixed, transformed or built upon. (https://creativecommons.org/ licenses/by-nc-nd/4.0/)

Thieme Revinter Publicações Ltda., Rua do Matoso 170, Rio de Janeiro, RJ, CEP 20270-135, Brazil 


\section{Introduction}

Septoplasty is one of the most common surgical procedures in rhinology practice. Septoplasty is not only performed for deviated nasal septum, but it is also commonly performed in endoscopic sinus surgery, endoscopic skull base surgery, or even in harvesting cartilage grafts for rhinoplasty and laryngotracheal reconstruction. During nasal septal surgery, different solutions can be infiltrated under the mucoperichondrium to reduce bleeding or to facilitate mucosal flap elevation. After the procedure, nasal packing is usually applied to stabilize the mucoperichondrial flaps, to control postoperative bleeding, and to prevent the formation of septal hematoma. However, the nasal packs may cause discomfort and intensify postoperative pain. ${ }^{1}$ Two major problems encountered after septoplasty are pain and bleeding. $^{2}$

To reduce postoperative pain, nonsteroidal anti-inflammatory drugs are usually prescribed. Also, there are attempts to soak the nasal packs with different local anesthetic solutions such as lidocaine, bupivacaine or ropivacaine to investigate the effect of these agents on postoperative pain. ${ }^{2}$ Lidocaine is a local anesthetic of the amide group that is widely used in infiltration anesthesia or nerve block. Its effect starts immediately, and it has a medium duration of action. Commercial preparation of lidocaine with adrenaline has a longer duration of action and, due to the vasoconstrictor effect of adrenaline, reduces hemorrhage. ${ }^{3}$

Pain management is a main issue after surgical interventions. For this purpose, the concept of multimodal analgesia has been introduced to reduce the need for oral or parenteral opioids and to reduce their side effects. ${ }^{4}$ Preoperative administration of analgesics before the surgical stimulus, which is the main concept of preemptive analgesia, decreases postoperative pain. ${ }^{5}$ Preemptive analgesia inhibits central sensitization due to surgical or inflammatory stimuli and covers both the perioperative and the early postoperative period. ${ }^{6}$ Different preemptive anesthesia techniques have been described, such as intramuscular, intravenous, local anesthetic injections, or wound infiltrations. ${ }^{7}$ Local anesthetic incisional infiltration is frequently used in different surgical operations. The local anesthetic agent can be infiltrated before the skin incision or following wound closure to facilitate postoperative pain control. For this purpose, bupivacaine or lidocaine can be used. ${ }^{4,8}$

However, lidocaine is preferable due to fewer side effects. ${ }^{9}$ Although used widely during septoplasty surgery, the possible preemptive effect of local lidocaine infiltration for the management of postoperative pain has not been studied. The present study was designed to investigate whether preincisional lidocaine infiltration in the subperichondrial area during septoplasty surgery reduced or not postoperative pain and analgesic use.

\section{Materials and Methods}

The present prospective, randomized, placebo controlled, double-blind trial was conducted on 64 consecutive patients with nasal septum deviation. All patients were admitted to Cerrahpaşa Medical Faculty Otorhinolaryngology Department between 2014 and 2015. The faculty ethics committee approved the study protocol and informed consent was obtained from each patient.

All of the patients in the present study were $>18$ years old and had nasal septum deviation without a previous history of nasal surgery. Patients with other medical conditions, bleeding disorders, receiving anticoagulants or frequent analgesics, patients with chronic pain syndromes, patients with caudal septum deviation or luxation of the columellar septum were excluded. All of the operations were performed under general anesthesia with thiopental $5 \mathrm{mg} / \mathrm{kg}$ and succinylcholine $1-1.5 \mathrm{mg} / \mathrm{kg}$, with ventilation of $50 \% 02$ and $50 \%$ N2O by the same surgical team with the same Killian incision. Silicone nasal splints were used in all patients, and the splints were retrieved after 3 days. None of the patients received routine premedication. The patients were randomly divided into 2 groups; the study group received $2 \% 20 \mathrm{mg}$ lidocaine/cc (Jetokain Simplex, ADEKA Pharmaceutical, Samsun, Turkey) $(n=31)$, and the control group received $6 \mathrm{cc} 0.9 \%$ $\mathrm{NaCl}(n=33)$. A computer program randomized the patients. The infiltration solutions were prepared by the nurse and handed to the surgeon at the time of infiltration. Neither the patient nor the surgeons were aware of the solution used. Before the incision, a standard $1 \mathrm{cc}$ infiltration in the incision site, along the septum under the perichondrium superiorly and inferiorly, perpendicular to the plate-quadrangular cartilage junction, the vomer area and the nasal floor along the septum. Eight minutes after the infiltration, the operations started and were completed by following standard surgical steps. After completion, each patient received a silicone nasal splint. After the operation, the patients were followed-up closely. A standard questionnaire was given to each patient to mark his or her pain score at the $1^{\text {st }}, 3^{\text {rd }}, 6^{\text {th }}, 12^{\text {th, }}$ and $24^{\text {th }}$ hours between 0 and 10 , where 0 meant no pain and 10 meant the worst pain that can be imagined (visual analogue scale [VAS]). During the hospital stay, analgesic (Dexketoprofen $50 \mathrm{mg}$ intravenous) use was ordered if the pain score was $>5$ or on demand. In the form, in-stay analgesic use (first use and total use) and the time of application were also recorded. After discharge, the patients were prescribed oral antibiotics and $50 \mathrm{mg}$ dexketoprofen orally and were instructed to record their use of analgesics for 72 hours.

The collected data were analyzed by IBM SPSS Statistics for Windows, version 21.0 (IBM Corp., Armonk, NY, USA). The comparison between subjects with preemptive analgesia and controls was performed by the nonparametric Mann Whitney U (Independent Groups Comparisons Test) test. Pvalues $<0.05$ were considered statistically significant.

\section{Results}

The study group was composed of 31 patients (22 male, 9 female) with ages ranging from 21to 59 years old, with a mean age of $33.19 \pm 9.7$, and the control group included 23 male and 10 female patients with a mean age of \pm 10.17 , without a significant difference $(p<0.05)(-$ Table 1$)$. 
Table 1 Comparison of the results of the two groups and p-values

\begin{tabular}{|c|c|c|c|}
\hline & $\begin{array}{l}\text { Study Group } \\
(n=31)\end{array}$ & $\begin{array}{l}\text { Control Group } \\
(n=33)\end{array}$ & p-value \\
\hline Gender (male/female) & $22 / 9$ & $23 / 10$ & \\
\hline $\begin{array}{l}\text { Age (years old) } \\
\text { (range and mean } \pm S D \text { ) }\end{array}$ & $\begin{array}{l}21-59 \\
33.19 \pm 9.7\end{array}$ & $\begin{array}{l}20-58 \\
32.78 \pm 10.17\end{array}$ & $>0.05$ \\
\hline $\begin{array}{l}1^{\text {st }} \text { postoperative hour VAS } \\
\text { (range and mean } \pm \text { SD) }\end{array}$ & $\begin{array}{l}0-10 \\
4.03 \pm 3.08\end{array}$ & $\begin{array}{l}0-10 \\
4.12 \pm 2.7\end{array}$ & 0.730 \\
\hline $\begin{array}{l}3^{\text {rd }} \text { postoperative hour VAS } \\
\text { (range and mean } \pm \text { SD) }\end{array}$ & $\begin{array}{l}0-8 \\
3.42 \pm 2.39\end{array}$ & $\begin{array}{l}0-10 \\
3.45 \pm 2.4\end{array}$ & 0.734 \\
\hline $\begin{array}{l}6^{\text {th }} \text { postoperative hour VAS } \\
\text { (range and mean } \pm \text { SD) }\end{array}$ & $\begin{array}{l}0-8 \\
2.97 \pm 2.22\end{array}$ & $\begin{array}{l}0-10 \\
2.94 \pm 2.7\end{array}$ & 0.744 \\
\hline $\begin{array}{l}12^{\text {th }} \text { postoperative hour VAS } \\
\text { (range and mean } \pm \text { SD) }\end{array}$ & $\begin{array}{l}0-9 \\
2.87 \pm 2.61\end{array}$ & $\begin{array}{l}0-10 \\
2.79 \pm 2.34\end{array}$ & 0.962 \\
\hline $\begin{array}{l}24^{\text {th }} \text { postoperative hour VAS } \\
\text { (range and mean } \pm \text { SD) }\end{array}$ & $\begin{array}{l}0-9 \\
1.94 \pm 2.06\end{array}$ & $\begin{array}{l}0-6 \\
1.5 \pm 1.8\end{array}$ & 0.284 \\
\hline $\begin{array}{l}1^{\text {st }} \text { IV analgesic time (hours) } \\
\text { (range and mean } \pm \text { SD) }\end{array}$ & $\begin{array}{l}0-24 \\
11.68 \pm 4.08 \\
\end{array}$ & $\begin{array}{l}0-24 \\
9.45 \pm 3.6\end{array}$ & 0.196 \\
\hline $\begin{array}{l}\text { Total number of IV analgesics } \\
\text { (range and mean } \pm \text { SD) }\end{array}$ & $\begin{array}{l}0-2 \\
0.87 \pm 0.71\end{array}$ & $\begin{array}{l}0-2 \\
1.03 \pm 0.76\end{array}$ & 0.398 \\
\hline $\begin{array}{l}\text { Total number of oral analgesics } \\
\text { (range and mean } \pm \text { SD) }\end{array}$ & $\begin{array}{l}0-4 \\
1.42 \pm 1.23\end{array}$ & $\begin{array}{l}0-4 \\
1.67 \pm 1.55\end{array}$ & 0.688 \\
\hline
\end{tabular}

Abbreviation: IV, Intravenous; SD, standard deviation ; VAS, visual analogue scale.

A $p$-value $<0.05$ is statistically significant.

The mean and the range of VAS scores of the patients in the study group at the $1^{\text {st }}, 3^{\text {rd }}, 12^{\text {th }}$, and $24^{\text {th }}$ hours were $4.03 \pm 3.08(0-10) ; \quad 3.42 \pm 2.39(0-8) ; 2.97 \pm 2.22(0-8)$; $2.87 \pm 2.61(0-9)$; and $1.94 \pm 2.06(0-9)$, respectively. The mean and the range of VAS scores of the patients in the control group at the $1^{\text {st }}, 3^{\text {rd }}, 12^{\text {th }}$, and $24^{\text {th }}$ hours were $4.12 \pm 2.7$ (0-10); $3.45 \pm 2.4(0-10) ; 2.94 \pm 2.7$ (0-10); $2.79 \pm 2.34(0-10)$; and $1.5 \pm 1.8(0-6)$, respectively. The statistical analysis revealed no significant difference among the groups (-Table $\mathbf{1}$ ).

The mean first IV analgesic use time of the patients in the study and control groups within the first 24 hours were 11.68 hours ( $0-24$ hours) and 9.45 hours (0-24), respectively, and the difference was not significant statistically (-Table 1).

The numbers of IV analgesic uses of the patients during the hospital stay were $0.87 \pm 0.71(0-2$ times $)$ and $1.03 \pm 0.76$ ( $0-2$ times), respectively, and the difference was not significant (-Table $\mathbf{1}$ ).

The mean number and range of the number of total analgesics used by the patients in the study and control groups were $1.42 \pm 1.23(0-4)$ and $1.67 \pm 1.55(0-4)$, respectively, with no significant difference (-Table 1 ).

\section{Discussion}

Postoperative pain management is the initial aspect of patient comfort following any surgery. To reduce postoperative pain and increase patient comfort, several methods can be used before procedures that are performed under general anesthesia. The opinions about the effectiveness of these methods, which have been routinely applied in many surgical disciplines, are often at the level of assumptions. Although the effectiveness of similar methods has been compared in studies performed within each surgical department, the consistency of the results and the pass-through between the departments is still controversial.

Postoperative pain following septoplasty results from the surgical wound, inflammation, and nasal packs that are used to prevent bleeding, formation of septal hematoma, and to stabilize the surgical field. In the literature, there are several studies that investigated different methods to reduce the pain and increase the comfort of the patient after septoplasty operation. These include infiltration anesthesia to the surgical field, infiltration of anesthetic agents to the nasal packs at the initial application of packs or during the follow-up period, preoperative oral or intravenous analgesic administration and inhalation of opioid drugs. According to a recently reported systematical review study, administration of local anesthetic agents to the nasal packs may reduce pain during the first 12 postoperative hours in septoplasty patients. However, it is not possible to state the same effect for the first 24 hours because the quality of the evidence is very low. ${ }^{8}$ According to the same systematic review, there is not sufficient evidence considering the effect of either preoperative infiltration anesthesia or sphenopalatine ganglion blockage, on postoperative pain.

In the literature, data that indicates the effectiveness of the preemptive infiltration anesthesia method we use is lacking. Our study was created to meet the need on this point.

In a study conducted by Mutlu et al., the superiority of local anesthetics infiltrated before septoplasty operation was 
investigated. According to the results of this study, significantly lower pain scores at the $1^{\text {st }}, 4^{\text {th }}, 8^{\text {th }}, 16^{\text {th }}$ and $24^{\text {th }}$ postoperative hours were obtained in all groups in which lidocaine, tetracaine, and articaine were administered, compared with the control group, which did not receive local anesthetics. As a result of comparing the pain scores on the $1^{\text {st }}$ postoperative day, articaine was reported to be superior to lidocaine and lidocaine to tetracaine. ${ }^{10}$ Our results did not support the results mentioned in this article; on the contrary, they were in agreement with the systematic review study mentioned earlier.

Other preemptive analgesia methods have also been tried to manage pain after nasal surgery. According to a study investigating the efficacy of preemptive analgesia with pregabalin in septoplasty patients, pain scores determined by the verbal numerical rating scale were significantly lower at the $1^{\text {st }}$ and $12^{\text {th }}$ postoperative hours in patients receiving pregabalin tablets. In addition, patients receiving pregabalin had less need for rescue analgesics in the postoperative period compared with the placebo group. ${ }^{11}$

In another study whose examples are more common in the literature but technically different from our study, it has been reported that infiltration of lidocaine into the nasal packs prior to the removal of the packs reduces the amount of pain during this procedure. ${ }^{12}$ The effect of the local anesthetic absorbed through the administration of nasal packs on postoperative pain was also investigated. In the evaluation made with the VAS scoring system, which was similar to that used in our study, it was stated that the group that received levobupivacaine absorbed through the administration of nasal packs felt less postoperative pain and needed significantly less analgesics than the control group. ${ }^{13}$

Preemptive inhaled analgesic administration is also among the methods whose effectiveness has been investigated. According to a study comparing the results between the morphine sulfate inhalation group with placebo before septoplasty and septorhinoplasty operation, the time to the first requirement for analgesia in the postoperative period was significantly longer in patients who inhaled morphine sulfate. ${ }^{5}$

The effects of local anesthetic infiltration on postoperative pain have also been investigated in other surgeries other than otolaryngology practice. In a study that is technically very similar to our study, it was stated that preemptive analgesia with lidocaine infiltration at the incision area decreased both postprocedure pain levels and postoperative opioid analgesic requirement in patients undergoing cesarean section. ${ }^{9}$ Similarly, in a study in which lidocaine plus epinephrine infiltration performed at the thoracotomy incision site was compared with only epinephrine infiltration, it was observed that the pain scores of the lidocaine group were lower in the postoperative 3-day follow-up, but the difference between the groups was not significant. ${ }^{14}$

Although a variety of methods have been used to provide preemptive analgesia, there are very few studies on this subject in the literature. We think that our study contributed to the literature in terms of evaluating the effectiveness of the infiltration method. If we interpret our results, the data obtained from the study group and the placebo group are very close to each other. The limited size of our working group is open to criticism, but we think that the reliability of the data we obtain from small and closely monitored groups is higher. In - Table $\mathbf{1}$ it can be seen how close the data obtained from the groups are. Accordingly, it would be more realistic to think that increasing the sample population would not be sufficient to make a statistical difference.

\section{Conclusion}

Preemptive local anesthetic administration to the incision area and under the mucoperichondrial flap before septoplasty does not decrease the level of postoperative pain.

Availability of Data and Material

The data of the study can be shared on demand.

Consent to Participate

All participants were informed and informed consent was retrieved.

\section{Consent for Publication}

All patients and all authors consented to the publication of the data.

\section{Ethics Approval}

The faculty ethics committee approved the study protocol and informed consent was obtained from each patient.

\section{Conflict of interests}

The authors have no conflict of interests to declare.

\section{References}

1 Watson MG, Campbell JB, Shenoi PM. Nasal surgery: does the type of nasal pack influence the results? Rhinology 1989;27(02): 105-111http://www.ncbi.nlm.nih.gov/pubmed/2781213

2 Karaman E, Gungor G, Alimoglu Y, et al. The effect of lidocaine, bupivacaine and ropivacaine in nasal packs on pain and hemorrhage after septoplasty. Eur Arch Otorhinolaryngol 2011;268(05): 685-689http://www.ncbi.nlm.nih.gov/pubmed/21120661

3 Kayhan Z. 20th Chapter. In: Clinical Anesthesia. 3rd ed. Logos; 2007:516-8

4 Hamilton TW, Athanassoglou V, Mellon S, et al. Liposomal bupivacaine infiltration at the surgical site for the management of postoperative pain [Internet]. Vol. 2017,. Cochrane Database of Systematic Reviews. John Wiley and Sons Ltd; 2017 [cited 2020 Mar 18]. p. CD011419. Available from: http://www.ncbi.nlm.nih.gov/pubmed/28146271

5 Onal SA, Keleş E, Toprak GC, Demirel I, Alpay HC, Avci L. Preliminary findings for preemptive analgesia with inhaled morphine: efficacy in septoplasty and septorhinoplasty cases. Otolaryngol Head Neck Surg 2006;135(01):85-89http://www.ncbi.nlm.nih. gov/pubmed/16815189

6 Kissin I. Preemptive analgesia. Vol. 93, Anesthesiology. Lippincott Williams and Wilkins; 2000:1138-43

7 Møiniche S, Kehlet H, Dahl JB. A qualitative and quantitative systematic review of preemptive analgesia for postoperative pain relief: the role of timing of analgesia. Anesthesiology 2002;96(03):725-741

8 Fujiwara T, Kuriyama A, Kato Y, Fukuoka T, Ota E. Perioperative local anaesthesia for reducing pain following septal surgery. 
Cochrane Database Syst Rev 2018;8(08):CD012047http://www. ncbi.nlm.nih.gov/pubmed/30136717

9 Sekhavat L, Behdad S. Preoperative analgesia with local lidocaine for cesarean delivery pain relief. J Matern Fetal Neonatal Med 2011;24 (07):891-893http://www.ncbi.nlm.nih.gov/pubmed/21219106

10 Mutlu V, Kaya Z. Comparison of the effect of the lidocaine, tetracaine, and articaine application into nasal packs on pain and hemorrhage after septoplasty. Eur Arch Otorhinolaryngol 2018;275(10):2481-2485http://www.ncbi.nlm.nih.gov/pubmed/30088077

$11 \mathrm{Kim}$ JH, Seo MY, Hong SD, et al. The efficacy of preemptive analgesia with pregabalin in septoplasty. Clin Exp Otorhinolaryngol 2014;7 (02):102-105http://www.ncbi.nlm.nih.gov/pubmed/24917905
12 Sahin C, Aras HI. Effect on patient anxiety of lidocaine infiltration into nasal packing after septoplasty: prospective, controlled study. J Laryngol Otol 2015;129(08):784-787

13 Yilmaz S, Kocaman Akbay B, Yildizbaş S, Güçlü E, Yaman H Yalçin Sezen G. Efficacy of topical levobupivacaine in control of postoperative pain after septoplasty. J Otolaryngol Head Neck Surg 2010;39(04):454-457http://www.ncbi.nlm.nih.gov/ pubmed/20643015

14 Cerfolio RJ, Bryant AS, Bass CS, Bartolucci AA. A prospective, double-blinded, randomized trial evaluating the use of preemptive analgesia of the skin before thoracotomy. Ann Thorac Surg 2003;76(04):1055-1058 